\title{
Culture-dependent approaches to explore the prevalence of root canal pathogens from endodontic infections
}

\section{Maryam POURHAJIBAGHER(a) Roghayeh GHORBANZADEH(b) Abbas BAHADOR ${ }^{(a)}$}

(a) Tehran University of Medical Sciences, Department of Microbiology, School of Medicine, Tehran, Iran.

(b)Private practice, Tehran, Iran.
Declaration of Interest: The authors certify that they have no commercial or associative interest that represents a conflict of interest in connection with the manuscript.

Abbas Bahador

E-mail: ab.bahador@gmail.com.

hitps://doi.org/10.1590/1807-3107bor-2017.vol31.0108

Submitted: June 15, 2017

Accepted for publication: Oct 10, 2017

Last revision: Nov 22, 2017

\begin{abstract}
Endodontic infections are considered to be caused by the presence of various microorganisms within the root canal system. Recognition of this microbiota contributes to the successful treatment of infected root canals. This study investigated the microorganisms associated with primary and secondary endodontic infections via culture methods, biochemical tests, and molecular approaches in an Iranian population. Microbial specimens were collected from 36 patients with primary endodontic infection and 14 patients with a history of root canal therapy. Advanced microbiological culture techniques were used to isolate microbiota; subsequently, biochemical tests and $16 \mathrm{~S}$ ribosomal RNA gene sequencing were performed to identify the microorganisms. Within the total 218 cultivable isolates, Veillonella parvula $(20.6 \%)$ was found to occur with the highest frequency in primary endodontic infection, followed by Porphyromonas gingivalis (14.1\%), and Aggregatibacter actinomycetemcomitans (9.2\%). Enterococcus faecalis (36.6\%) was the most predominant microorganism in secondary endodontic infections, followed by Candida albicans, Propionibacterium acnes, and V. parvula with frequencies of $20 \%, 2 \%$, and $2 \%$, respectively. It was concluded that $V$. parvula and E. faecalis was most frequently found in primary and secondary endodontic infections, respectively.
\end{abstract}

Keywords: Endodontic Infections, Facultative Anaerobic Bacteria, Infected Root Canal, Obligate Anaerobic Bacteria, 16S rRNA Gene Sequencing

\section{Introduction}

Endodontic disease is caused by the presence of a polymicrobial consortium within the root canal system. ${ }^{1}$ The available evidence has successfully demonstrated the role of etiological agents of endodontic origin in the initiation of periapical inflammation. ${ }^{2,3}$

The microorganisms, in particular Gram-negative, predominantly anaerobic, bacteria, that are able to initially colonize the dental pulp tissue cause primary infection, whereas those present in the treated root canal system are the etiological agents responsible for secondary infections. ${ }^{4}$

On the basis of the results of previous studies, the microbial communities in primary endodontic infections are more diverse than those in secondary endodontic infections. ${ }^{5,6,7}$ Moreover, variation in the microorganisms isolated in several studies is likely a result of differences in the sampling techniques, laboratory procedures, and diagnostic approaches. ${ }^{8}$ 
The therapy for infected root canals aims to identify the existing microbiota in endodontic infections and to disrupt and eliminate the microbiota in the root canal system, particularly for primary and secondary endodontic infections. ${ }^{4}$

Understanding the microbiota composition in the infected root canal is essential for improving the treatment strategies to control infections and eliminate the pathogenic agents, as well as to prevent reinfection and periapical lesions. ${ }^{9}$

The type and frequency of microbial agents involved in the genesis of endodontic diseases depend on several factors, such as geographic location, socioeconomic status, dietary habits, and oral hygiene status. ${ }^{10}$ To the best of our knowledge, no study in Iran has explored this topic to date. Therefore, in the present study, we investigated the microorganisms associated with the primary and secondary endodontic infections via culture methods, biochemical tests, and molecular approaches in an Iranian population.

\section{Methodology}

\section{Patient selection}

Patients who visited a private dental clinic in Tehran, Iran, for root canal treatment and nonsurgical endodontic retreatment were considered for this study. Those who used antimicrobial agents within the preceding 30 days of their visit; aged less than 18 years with incomplete development of the root apex; with root canal curve and multi-rooted canal, extensive dental caries and coronal leakage, periodontal pockets greater than $4 \mathrm{~mm}$, advanced bone loss, severe systemic disease, such as diabetes mellitus, cardiovascular diseases, and immune-compromised cases; and who were pregnant or lactating were excluded from this study. All the selected patients provided written informed consent. Approval for the study protocol was obtained from the Ethics Committee of the Iranian Registry of Clinical Trials (IRCT ID: IRCT2015031321455N1).

\section{Clinical procedures and sample collection}

In patients who were referred to the dental clinic for the first time for root canal therapy, the teeth were individually isolated with a previously disinfected rubber dam. After the removal of existing restorations and caries with sterile high-speed and low-speed burs and removal of the supragingival plaque by scaling and cleansing with pumice, the tooth and the surrounding field were disinfected with $30 \%$ hydrogen peroxide for $30 \mathrm{~s}$ followed by $2.5 \%$ sodium hypochlorite solution for an additional $30 \mathrm{~s}$. Subsequently, the disinfectant was inactivated with sterile $5 \%$ sodium thiosulphate to avoid interference with microbiological analysis.

After preparation of the access to the root canal using sterile burs without water spray, the root canal was enlarged using a hand K-type file (Dentsply Maillefer, Ballaigues, Switzerland) with minimal instrumentation where possible, and a sterile paper point was placed in the full length of the canal for 60 $\mathrm{s}$. The paper point was transferred aseptically to tubes containing Viability Medium Göteborg Agar (VMGA) III transport medium; this was then transferred to the microbiology laboratory within $15 \mathrm{~min}$. To ensure viable sample acquisition in cases where the root canal was dry, a small amount of sterile normal saline was applied into the canal. No irrigants were used in this study before microbiological sampling. ${ }^{11,12}$

In patients who were referred for endodontic retreatment, prior to rubber dam application all coronal restorations, carious defects, and posts were completely removed. As mentioned above, a rubber dam was used and the root filling materials were extracted using Gates-Glidden drills and rotary instrumentation; the endodontic K-type files were prepared without the use of chemical solutions. Subsequently, a sterile normal saline solution was applied to eliminate treatment residues prior to microbial sampling. Electronic apex locator was used to determine working length and a sterile paper point No. 30 was subsequently placed in the entire canal. The paper point was retained for $60 \mathrm{~s}$ and was immediately transferred aseptically to the VMGA III transport medium; this was taken to the microbiology laboratory within $15 \mathrm{~min} .{ }^{13}$

\section{Culture analysis of the microbiota}

An anaerobic atmosphere $\left(90 \% \mathrm{~N}_{2}, 5 \% \mathrm{H}_{2}\right.$, and $5 \% \mathrm{CO}_{2}$ ) was maintained throughout the sample processing and microbiological procedures using 
an anaerobic chamber (UniEquip $\mathrm{GmbH}$, BacBASIC, Germany). The culture method was conducted in accordance with a previous study. ${ }^{14}$ Briefly, the vials containing the root canal samples in the VMGA III transport medium were strongly vortexed for $30-45 \mathrm{~s}$ and diluted ten-fold, as described elsewhere. ${ }^{14,15,16}$ All the wells of round-bottom 96-well microtiter plates (TPP, Trasadingen, Switzerland) were filled with 90 microliter $(\mu \mathrm{L})$ brain heart infusion (BHI) broth (Merck, Darmstadt, Germany). Next, $10 \mu \mathrm{L}$ of each sample was transferred to the wells in column 1 and was diluted ten-fold stepwise from column 1 to column 5 . Subsequently, $10 \mu \mathrm{L}$ of the serially diluted suspension was plated onto the BHI agar plates (Merck, Darmstadt, Germany) supplemented with 5\% defibrinated sheep blood, $0.6 \%$ (wt/vol) yeast extract (Merck, Darmstadt, Germany), $5 \mathrm{mg} / \mathrm{L}$ hemin, and $1 \mathrm{mg} / \mathrm{L}$ menadione (both purchased from Sigma-Aldrich, Steinheim, Germany) using spread culture technique. Next, plates of each sample were immediately transferred to anaerobic jars (Anoxomat System, WS9000; Mart, The Netherlands), which were evacuated and filled three times with an anaerobic atmosphere $\left(90 \% \mathrm{~N}_{2}, 5 \% \mathrm{H}_{2}\right.$, and $5 \% \mathrm{CO}_{2}$ ). The anaerobic jars were incubated in a traditional incubator for up to 7 days at $37^{\circ} \mathrm{C}$. The same dilutions were plated on the $\mathrm{BHI}$ agar containing $5 \%$ defibrinated sheep blood (sBHI agar) for the growth of the aerobic and/or facultative bacteria and on Sabouraud dextrose agar (SD agar; Oxoid, Basingstoke, UK) containing 100 $\mu \mathrm{g} / \mathrm{mL}$ chloramphenicol for the detection of Candida spp;; both the sBHI agar and SD agar were incubated at $37^{\circ} \mathrm{C}$ for $24-48 \mathrm{~h}$ under aerobic conditions. Colony types were observed, and the total number of colony forming units (CFUs)/mL was calculated using Miles and Misra method in the original sample. ${ }^{17}$ Finally, all colony types were sub-cultivated to acquire pure cultures for identification.

\section{Microbial identification}

Gram staining was performed on the pure root canal isolates, and the microbial morphology such as size, shape, texture, and elevation were determined using bright field microscopy (Olympus, Japan; 1000× magnification). Routine biochemical tests were performed for identification of aerobic and facultative anaerobic bacteria. To identify the anaerobic bacteria, biochemical characteristics were analyzed with the analytical profile index (API ${ }^{\circledR}$ 20A) assays (BioMerieux, Marcy l'Etoile, France). All the procedures for the identification of these microorganisms were conducted according to the CLSI (Clinical and Laboratory Standard Institute) guidelines. ${ }^{18}$ Moreover, $16 \mathrm{~S}$ ribosomal RNA (16S $r R N A$ ) gene sequencing was performed for anaerobic isolates that could not be identified using the API ${ }^{\circledR}$ $20 \mathrm{~A}$ methods, according to a previous study. ${ }^{14}$

\section{PCR amplification of 16S rRNA and sequence analysis}

Genomic DNA was extracted from each isolate using DNA extraction kit (Thermo Fisher Scientific, USA), according to the manufacturer's instructions. The PCR amplification was performed in a total volume of 25 $\mu \mathrm{L}$ with AccuPower Pfu PCR Premix (Bioneer, Korea) and with universal targeting of $16 S \mathrm{r} R \mathrm{RA}$. The primers used were 5'-AGAGTTTGATCCTGGCTCAG-3' and 5'-AAGGAGGTGATCCAGCCGCA-3', corresponding to base positions from 1520 to 1550 . PCR cycling conditions comprised an initial denaturation step at $95^{\circ} \mathrm{C}$ for 5 min, followed by 35 cycles with denaturation at $95^{\circ} \mathrm{C}$ for $40 \mathrm{~s}$, annealing at $53^{\circ} \mathrm{C}$ for $40 \mathrm{~s}$, and extension at $72^{\circ} \mathrm{C}$ for $1 \mathrm{~min}$, with a final extension step at $72^{\circ} \mathrm{C}$ for $5 \mathrm{~min}$. Positive and negative controls were included in each set of PCR reactions. PCR reaction products were analyzed by $1.5 \%$ agarose gel electrophoresis in Trisacetate-EDTA (TAE) buffer ( $40 \mathrm{mM}$ Tris-acetate, $2 \mathrm{mM}$ EDTA [pH 8.3]), stained with $0.1 \mu \mathrm{g}$ of safety dye per $\mathrm{mL}$, and photographed under ultraviolet (UV) light. Thereafter, the PCR products were sequenced on the basis of the conserved fragment of the $16 \mathrm{~S} r R N A$ gene using an ABI3730 automatic sequencer (Applied Biosystems, CA, USA). Subsequently, the Basic Local Alignment Search Tool (BLAST) against the National Center for Biotechnology Information GenBank database (http:// www.ncbi.nlm.nih.gov/guide/dna-rna/) was used to analyze the sequencing results (accessed 02.06.16).

\section{Statistical analysis}

Data were analyzed using SPSS 23.0 (SPSS Inc., Chicago, IL, USA). The results were statistically evaluated using Student's unpaired t-test and Pearson chi-square test. 


\section{Results}

Of the 50 patients participating in this study, 29 were male and 21 were female, with an age range of 21-62 years (mean, $42.1 \pm 8.4$ years). Of the total, 36 were infected by primary endodontic infection and 14 had a history of root canal therapy. Overall, 218 cultivable isolates were collected from root canals, including $184(84.4 \%)$ and 30 (15.6\%) isolates from the primary and secondary endodontic infection, respectively, that belonged to 14 different genera and 20 various microbial species.

The prevalence of microbiota among the isolated strains were $46.3 \%$ strict anaerobes, $37.1 \%$ facultative anaerobes, $10.5 \%$ microaerophilic, and $5.9 \%$ aerobic microorganisms (Figure 1).

Approximately $96.3 \%$ of microbial isolates were identified using biochemical analysis and $\mathrm{API}^{\circledR} 20 \mathrm{~A}$ Kit. Among anaerobic isolates, 8 (3.7\%) isolates were identified by $16 S$ rRNA gene sequencing (Figure 2), and the data were registered in the GenBank database with the accession numbers shown in Table 1.

Ofall theidentified taxa, six (Slackia exigua, Pseudomonas aeruginosa, Streptococcus mutans, Campylobacter curvus, Klebsiella pneumoniae, and Staphylococcus epidermidis) were found only in primary root canal infections.

According to the results presented in Figure 1, Veillonella parvula was found to have thehighest frequency and distribution in primary endodontic infections (38/184; 20.6\%), followed by Porphyromonas gingivalis (26/184; 14.1\%), and Aggregatibacter actinomycetemcomitans (17/184; $9.2 \%)$, with other bacteria representing less than $8 \%$ of the total microorganisms (Figure 1). Enterococcus faecalis, Candida albicans, Propionibacterium acnes, and $V$. parvula were the most common microorganisms in the secondary infected root canals with a frequency of $36.6 \%, 20 \%, 2 \%$, and $2 \%$, respectively.

The microbial count ranged from $1 \times 10^{3} \mathrm{CFU} /$ $\mathrm{ml}$ to $3.8 \times 10^{4} \mathrm{CFU} / \mathrm{ml}$ for either strict anaerobes or microaerophilic cultivation (mean $=2.5 \times 10^{3} \mathrm{CFU} /$ $\mathrm{mL}$ ) and from $1 \times 10^{3} \mathrm{CFU} / \mathrm{mL}$ to $5.8 \times 10^{4} \mathrm{CFU} / \mathrm{mL}$ for aerobic cultivation (mean $=4.2 \times 10^{3} \mathrm{CFU} / \mathrm{mL}$ ). The number of microbial species obtained varied from 1 to $3($ mean $=2.1)$ per sample in primary endodontic infections and from 2 to 7 (mean $=4.6$ ) per sample in the secondary infected root canals.

\section{Discussion}

Previous studies suggest that the community profiles of microbiota in infected root canals play a more important role in the progression and perpetuation of diseases than single species. ${ }^{19}$

Understanding the endodontic microbiota is an essential requirement for clinicians to choose an effective treatment strategy for patients. ${ }^{20}$

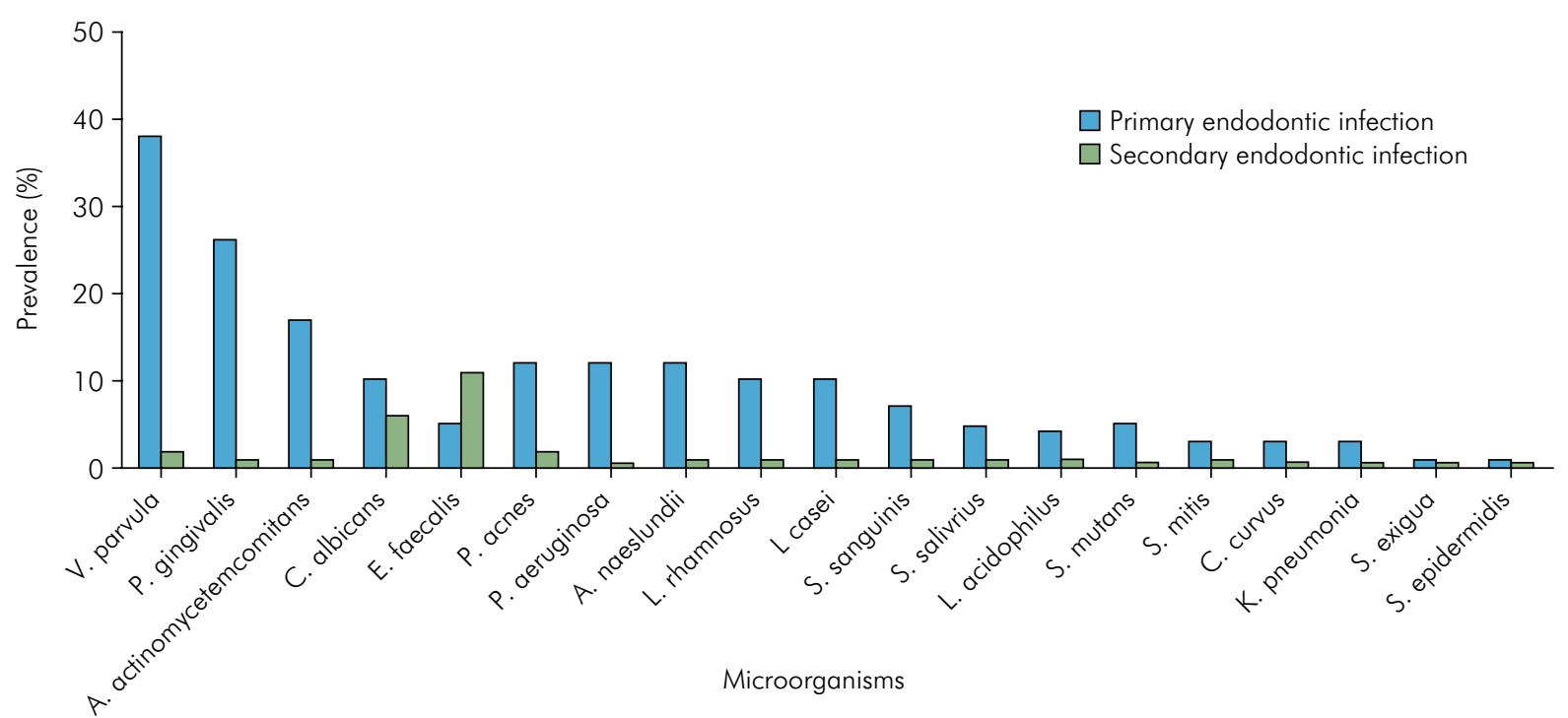

Figure 1. The distribution of microorganisms isolated from patients with primary and secondary endodontic infections. 


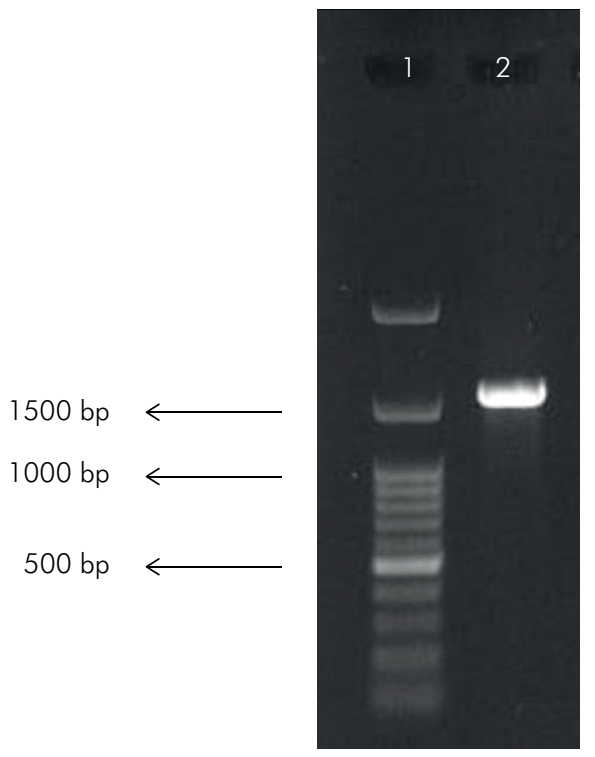

Figure 2. DNA amplification patterns obtained with universally targeting $16 \mathrm{~S}$ rRNA on $2 \%$ agarose gel. Lane 1: Ladder 100 bp, Lane 2: an unknown isolate.

Table 1. Accession numbers of obligatory anaerobic bacteria registered in the GenBank database (http://www.ncbi.nlm.nih. gov/guide/dna-rna/).

\begin{tabular}{cc}
\hline Accession number & Organism \\
\hline KT989507 & Slackia exigua \\
KX108928 & Aggregatibacter actinomycetemcomitans \\
KX108929 & Porphyromonas gingivalis \\
KX108930 & Propionibacterium acnes \\
KX108934 & Veillonella parvula \\
KU550132 & Veillonella parvula \\
KU550133 & Campylobacter curvus \\
KU550134 & Slackia exigua \\
\hline
\end{tabular}

Because the microbiota that colonize the infected root canals vary with the geographic location of the patients studied, to date, there are no comparative data for the microorganisms associated with primary and secondary endodontic infections worldwide. This study was performed among the Iranian population using an advanced culturing technique.

In the present study, microorganisms were recovered from 50 root canals examined. Cultivation was used as the most accurate method to disclose a wider spectrum of microorganisms in the root canal system and was able to measure viable bacterial cells as CFUs. ${ }^{21}$ Alternatively, this conventional test method is not only easily adaptable, practical, and inexpensive but also has been previously shown to be highly effective. ${ }^{14}$

In this study, Gram-negative bacteria accounted for $60.3 \%$ and $16.6 \%$ of the total species isolated for primary and secondary infected root canals, respectively. The results of this study showed that the majority of species found in primary root canal infections belonged to obligate Gram-negative anaerobic bacteria. Some of the species found, for example, S. exigua, P. aeruginosa, S. mutans, C. curous, K. pneumoniae, and S. epidermidis, were isolated only from primary endodontic infections in the present study. Several investigations have revealed the presence of microbial diversity in root canal infections, which matched with the results of the present study. Silva et al..$^{22}$ and Gomes et al. ${ }^{12}$ also reported that the majority of species found in primary endodontic infections belonged to the strict anaerobes or microaerophilic bacteria. In contrast, the results of secondary endodontic infections in this study have included several representatives of facultative anaerobic bacteria. The findings of this study revealed bacterial colonization in treated root canals to occur within $15.6 \%$ cases, which is in line with previous studies. ${ }^{11,23,24}$ E. faecalis isolates were the most frequently recovered bacterial species from treated root canals, which is consistent with the findings of Molander et al. ${ }^{25}$, Peciuliene et al. ${ }^{26}$, Pinheiro et al. ${ }^{27}$, and Gomes et al. ${ }^{12}$. Other microorganisms isolated abundantly from the secondary endodontic infections include $C$. albicans, $P$. acnes, and $V$. parvula. Łysakowska et al. ${ }^{28}$ reported that enterococci and streptococci were the most commonly isolated bacteria from root canals with secondary infections.

The findings of these studies confirm the polymicrobial nature of endodontic infections and reveal that the diversity of the microbiota, number, and species not only of primary endodontic infections but also of secondary infections is widely researched to date. ${ }^{24,25,26,27,28}$ The microorganisms related to the primary and secondary endodontic infections differed because of the changes in ecology of the root canal system. Primary infections of root canals are caused by microorganisms colonizing the pulp tissue, whereas microorganisms that can survive against biochemical 
disinfectant materials or invade the canal through the coronal leakage of the root canal filling are present in secondary infected canals. ${ }^{29}$ In addition, the resistance of microorganisms to antimicrobial chemical agents and root canal irrigants with broad antibacterial activity can lead to secondary infections; therefore, these organisms can persist more frequently in the root canal following incomplete root canal preparation and obturation. ${ }^{30}$

Despite the importance of culture-based methods in the surveillance of microbial diversity profiles for primary and secondary endodontic infections, it is possible that some microorganisms present in the root canal infections could be lost during surveillance, particularly if the microbial count is low. ${ }^{27}$ Therefore, it is recommended that an alternative and sensitive non-culture-based method should be used.

Collectively, the results of this study suggest that future surveys from multiple dental clinics along with modern and advanced molecular assays are needed to provide a clear view of the microbiota in the endodontic

\section{References}

1. Vengerfeldt V, Špilka K, Saag M, Preem JK, Oopkaup K, Truu J et al. Highly diverse microbiota in dental root canals in cases of apical periodontitis (data of illumina sequencing). J Endod. 2014;40(11):1778-83. https://doi.org/10.1016/i.joen.2014.06.017

2. Aw $\mathrm{V}$. Discuss the role of microorganisms in the aetiology and pathogenesis of periapical disease. Aust Endod J. 2016;42(2):53-9. https://doi.org/10.1111/aej.12159

3. Siqueira JF Jr, Rôças IN. Microbiology and treatment of acute apical abscesses. Clin Microbiol Rev. 2013;26(2):255-73. https://doi.org/10.1128/CMR.00082-12

4. Arias MP, Maliza AG, Midena RZ, Graeff MS, Duarte MA, Andrade $\mathrm{FB}$. Effect of ultrasonic streaming on intra-dentinal disinfection and penetration of calcium hydroxide paste in endodontic treatment. J Appl Oral Sci. 2016;24(6):575-81. https://doi.org/10.1590/1678-775720150553

5. Tennert C, Fuhrmann M, Wittmer A, Karygianni L, Altenburger MJ, Pelz K et al. New bacterial composition in primary and persistent/secondary endodontic infections with respect to clinical and radiographic findings. J Endod. 2014 May;40(5):670-7. https://doi.org/10.1016/i.joen.2013.10.005

6. Nóbrega LM, Montagner F, Ribeiro AC, Mayer MA, Gomes BP. Bacterial diversity of symptomatic primary endodontic infection by clonal analysis. Braz Oral Res. 2016;30(1):e103:1-9. https:// doi.org/10.1590/1807-3107BOR-2016.vol30.0103. infections and lead to a better prognosis for root canal retreatments. Notably, the major limitation of this study was that few patients were accessed because of the stringent inclusion criteria.

\section{Conclusions}

To date, no studies have reported the prevalence and variety of microorganisms associated with endodontic infections in the Iranian population. Our results in this study showed a variety of microorganisms in infected root canals, with the obligatory anaerobic bacterium $V$. parvula and the facultative anaerobic bacterium $E$. faecalis having the highest prevalence in primary and secondary endodontic infections, respectively.

\section{Acknowledgment}

This research has been supported by Tehran University of Medical Sciences \& Health Services grant No. 93-04-30-27681.

7. Tzanetakis GN, Azcarate-Peril MA, Zachaki S, Panopoulos P, Kontakiotis EG, Madianos PN et al. Comparison of Bacterial Community Composition of Primary and Persistent Endodontic Infections Using Pyrosequencing. J Endod. 2015;41(8):1226-33. https://doi.org/10.1016/i.joen.2015.03.010

8. Didilescu AC, Rusu D, Anghel A, Nica L, Iliescu A, Greabu $M$ et al. Investigation of six selected bacterial species in endo-periodontal lesions. Int Endod J. 2012 r;45(3):282-93. https://doi.org/10.1111/j.1365-2591.2011.01974.x

9. Hong BY, Lee TK, Lim SM, Chang SW, Park J, Han SH ef al. Microbial analysis in primary and persistent endodontic infections by using pyrosequencing. J Endod. 2013;39(9):113640. https://doi.org/10.1016/i.joen.2013.05.001

10. Maltz M, Jardim JJ, Alves LS. Health promotion and dental caries. Braz Oral Res. 2010;24(1 Suppl 1):18-25. https://doi.org/10.1590/S1806-83242010000500004

11. Gomes BP, Pinheiro ET, Gadê-Neto CR, Sousa EL, Ferraz CC, Zaia AA et al. Microbiological examination of infected dental root canals. Oral Microbiol Immunol. 2004;19(2):71-6. https://doi.org/10.1046/j.0902-0055.2003.00116.x

12. Gomes BP, Drucker DB, Lilley JD. Associations of specific bacteria with some endodontic signs and symptoms. Int Endod J. 1994;27(6):291-8. https://doi.org/10.1111/j.1365-2591.1994.tb00271.x 
13. Vidana R, Sullivan A, Billström H, Ahlquist M, Lund B. Enterococcus faecalis infection in root canals - host-derived or exogenous source? Lett Appl Microbiol. 2011;52(2):109-15. https://doi.org/10.1111/j.1472-765X.2010.02972.x

14. Pourhajibagher M, Ghorbanzadeh R, Parker S, Chiniforush $\mathrm{N}$, Bahador A. The evaluation of cultivable microbiota profile in patients with secondary endodontic infection before and after photo-activated disinfection. Photodiagn Photodyn Ther. 2017;18:198-203. https://doi.org/10.1016/i.pdpdt.2017.02.013

15. Pourhajibagher $M$, Chiniforush N, Raoofian R, Pourakbari $B$, Ghorbanzadeh R, Bazariani F et al. Evaluation of photoactivated disinfection effectiveness with methylene blue against Porphyromonas gingivalis involved in endodontic infection: an in vitro study. Photodiagn Photodyn Ther. 2016;16:132-5. https://doi.org/10.1016/i.pdpdt.2016.09.008

16. Pourhajibagher M, Chiniforush N, Ghorbanzadeh R, Bahador A. Photo-activated disinfection based on indocyanine green against cell viability and biofilm formation of Porphyromonas gingivalis. Photodiagn Photodyn Ther. 2017;17:61-4. https://doi.org/10.1016/i.pdpdt.2016.10.003

17. Miles AA, Misra SS, Irwin JO. The estimation of the bactericidal power of the blood. J Hyg (Lond). 1938;38(6):732-49. https://doi.org/10.1017/S002217240001158X

18. Clinical and Laboratory Standards Institute. M100-S25: performance standards for antimicrobial susceptibility testing; twenty-fiftth informational supplement. Wayne: Clinical and Laboratory Standards Institute; 2015.

19. Anderson AC, Hellwig E, Vespermann R, Wittmer A, Schmid $M$, Karygianni $L$ et al. Comprehensive analysis of secondary dental root canal infections: a combination of culture and culture-independent approaches reveals new insights. PLoS One. 2012;7(11):e49576:1-12.

20. Matsui A, Jin JO, Johnston CD, Yamazaki H, Houri-Haddad $Y$, Rittling SR. Pathogenic bacterial species associated with endodontic infection evade innate immune control by disabling neutrophils. Infect Immun. 2014;82(10):4068-79. https://doi.org/10.1128/IAl.02256-14

21. Peciuliene V, Maneliene R, Balcikonyte E, Drukteinis S, Rutkunas $V$. Microorganisms in root canal infections: a review. Stomatologija. 2008;10(1):4-9.
22. Silva LA, Leonardo MR, Oliveira DS, Silva RA, Queiroz AM, Hernández PG et al. Histopathological evaluation of root canal filling materials for primary teeth. Braz Dent J. 2010;21(1):38-45. https://doi.org/10.1590/S0103-64402010000100006

23. Gajan EB, Aghazadeh M, Abashov R, Salem Milani A Moosavi Z. Microbial flora of root canals of pulpallyinfected teeth: Enterococcus faecalis a prevalent species. J Dent Res Dent Clin Dent Prospects. 2009;3(1):24-7. https://doi.org/10.5681/joddd.2009.007

24. Ercan E, Dalli M, Yavuz I, Ozekinci T. Investigation of microorganisms in infected dental root canals. Biotechnol Biotechnol Equip. 2006;20(2):166-72. https://doi.org/10.1080/13102818.2006.10817361

25. Molander A, Reit C, Dahlén G, Kvist T.

Microbiological status of root-filled teeth with apical periodontitis. Int Endod J. 1998;31(1):1-7. https://doi.org/10.1046/i.1365-2591.1998.t01-1-00111.x

26. Peciuliene V, Balciuniene I, Eriksen HM, Haapasalo M. Isolation of Enterococcus faecalis in previously root-filled canals in a Lithuanian population. J Endod. 2000;26(10):593-5. https://doi.org/10.1097/00004770-200010000-00004

27. Pinheiro ET, Gomes BP, Ferraz CC, Sousa EL, Teixeira FB, Souza-Filho FJ. Microorganisms from canals of root-filled teeth with periapical lesions. Int Endod J. 2003;36(1):1-11. https://doi.org/10.1046/i.1365-2591.2003.00603.x

28. Łysakowska ME, Ciebiada-Adamiec A, Sienkiewicz M, Sokołowski J, Banaszek K. The cultivable microbiota of primary and secondary infected root canals, their susceptibility to antibiotics and association with the signs and symptoms of infection. Int Endod J. 2016;49(5):422-30. https://doi.org/10.1111/iej.12469

29. Estrela C, Holland R, Estrela CR, Alencar AH, SousaNeto MD, Pécora JD. Characterization of successful root canal treatment. Braz Dent J. 2014;25(1):3-11. https://doi. org/10.1590/0103-6440201302356PMID:24789284

30. Pourhajibagher $M$, Bahador $A$. Is antimicrobial agents can considered as effective weapons against endodontic infections by Enterococcus faecalis? Pharma Chem. 2015;7:196-200. 